\title{
Serum Calcium is Related to the Degree of Artery Stenosis in Acute Ischemic Stroke
}

\author{
Jiayan Wua Junchao Xie Yanxin Zhao $^{\mathrm{a}} \quad$ Li Gong $^{\mathrm{a}} \quad$ Xueyuan Liu ${ }^{\mathrm{a}}$ Wangmi Liu ${ }^{\mathrm{b}}$ \\ aDepartment of Neurology, Shanghai Tenth People's Hospital, School of Medicine, Tongji University,

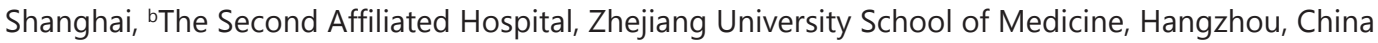

\author{
Key Words \\ Calcium • Stenosis $\bullet$ Stroke $・$ Microarray analysis
}

\begin{abstract}
Background/Aims: Acute ischemic stroke is caused by stenosis of artery supplying to brain. We aimed to detect some metabolites in the serum that would be related to the degree of artery stenosis and to analyze potential mechanisms. Methods: Patients diagnosed with acute ischemic stroke were divided into two groups according to their degree of artery stenosis (which was determined by computed tomographic angiography): a mild group (stenosis $\leq$ $30 \%$ ) and a severe group (stenosis $>30 \%$ ). Serum from these patients was collected, and we focused on the differences in the concentrations of calcium, uric acid, low density lipoprotein and homocysteine. The dataset GSE11583 from the Gene Expression Omnibus database was analyzed to find the potential mechanism using bioinformatics methods. Results: Among the four metabolites, the only difference that reached significance between the two groups was in the concentration of calcium in serum $(2.27 \pm 0.08 \mathrm{mmol} / \mathrm{L}$ vs $2.21 \pm 0.08 \mathrm{mmol} / \mathrm{L})$. By comparing the gene expression levels between normal endothelial cells and adaptive remodeling endothelial cells in GSE11583, we identified 51 upregulated and 40 downregulated genes in adaptive remodeling endothelial cells. The gene set enrichment analysis revealed that upregulated genes were enriched in a phosphatidylinositol signaling system, which is closely involved in the calcium signaling pathway. Conclusion: Our results suggest that the concentration of serum calcium is higher in patients with more severe artery stenosis lesions and that the phosphatidylinositol signaling system is a key biological pathway involved in this process.

\section{Introduction}

Acute ischemic stroke is one of the leading causes of long-term disability and death. The advent of thrombolytic therapy for acute ischemic stroke led to the standard therapies that are available now [1]. However, thrombolytic agents must be administered within 3-6 h of symptom occurrence. Therefore, less than $10 \%$ of stroke patients can get to a hospital in the narrow therapeutic time-window after symptom onset for acute intervention [2]. For those

Wangmi Liu and Xueyuan Liu 
patients who failed to receive thrombolytic therapy, blood flow could reach the ischemic area through other blood vessels, which is called collateral circulation when the cerebral blood supply decreases due to artery stenosis or occlusion.

Many studies have revealed that status of collateral circulation is related to infarction volume, risk of stroke recurrence, and prognosis $[3,4]$. Overall, the existence of effective cerebral collateral circulation can supply the territories with occluded arteries, which will result in less infraction volume and a smaller size of the ischemic penumbra. Therefore, previous studies focused on direct visualization of collateral circulation, including conventional angiography $[5,6]$, magnetic resonance angiography $[7,8]$, transcranial Doppler (TCD) $[9,10]$, and computer tomography angiography (CTA) [11]. Abnormal hemodynamic parameters have been detected in collateral circulation after acute ischemic stroke using TCD [12]. Nevertheless, few studies have focused on the effects of turbulent collateral blood flow on endothelial cells. Considering the important role of hemodynamic shear stress in the physiological and pathological vascular functions through endothelial mechano-activation $[13,14]$, we aimed to conduct a study of the effects of turbulent collateral blood flow on the endothelial cells after acute ischemic stroke from the perspective of metabolism.

In this study, we divided patients with acute ischemic stroke into two groups according their degree of artery stenosis as determined by CTA. The concentrations of calcium, uric acid, low density lipoprotein and homocysteine in serum between the two groups were compared. To reveal the potential underlying mechanism, we analyzed the dataset GSE11583 from the Gene Expression Omnibus (GEO) database using bioinformatics methods.

\section{Materials and Methods}

\section{Patients and Samples}

We retrospectively screened acute ischemic stroke patients at the Department of Neurology of Shanghai Tenth People's Hospital at Tongji University between January 2015 and December 2016. The study received ethical approval from the Ethics Committee. The selection criteria were as follows:

Inclusion Criteria:

1. Age greater than or equal to 30 years old.

2. Time of stroke onset less than 2 days.

3. Failure to receive thrombolytic therapy.

4. Acute cerebral infarction due to the stenosis or occlusion of cerebral artery diagnosed by CTA.

5. National Institute of Health Stroke Scale (NIHSS) score of 5 to 20.

Exclusion Criteria:

1. NIHSS score of less than 5 or more than 20.

2. Patients with a cerebral aneurysm, cerebral hemorrhage, brain tumor, brain contusion.

3. Intracranial hemorrhage as shown in a CT or MRI.

4. Cardiac insufficiency.

5. Chronic liver disease or alanine aminotransferase 1.5 times higher than the normal value.

6. Chronic kidney disease or serum creatinine 1.5 times higher than the normal value.

7. Poorly controlled diabetes.

According to the inclusion and exclusion criteria, eligible subjects' basic information and medical history, such as the results of CTA and blood sample tests, were collected.

\section{Imaging}

Within 48 hours after the onset of acute ischemic stroke, patients were subjected to receive CTA examination. The patients were given a single bolus IV contrast injection of $50 \mathrm{~mL}$ nonionic contrast media into their antecubital vein. CT scans were obtained at a $1.3-\mathrm{mm}$ slice thickness with a 1-mm interval. Then, 2D images were reconstructed to get 3D images. The degree of stenosis was defined as the narrowest vessel diameter divided by a normal adjacent diameter of the vessel [15]. Stenosis less than $30 \%$ was considered mild, while stenosis greater than $30 \%$ was considered to be severe [16]. Two blinded and specially trained raters, who were not aware of the patients' clinical condition, performed the patient classification 


\section{Cellular Physiology Cell Physiol Biochem 2018;46:1189-1197 \\ and Biochemistry Published $\begin{aligned} & \text { DOI: 10.1159/000489069 } \\ & \text { (c) } 2018 \text { The Author(s). Published by S. Karger AG, Basel } \\ & \text { www.karger.com/cpb }\end{aligned}$ \\ Wu et al.: Serum Calcium and Artery Stenosis}

independently using the relevant images from CTA. If there was a discrepancy between the two raters, reevaluation was conducted and joint decision was made.

\section{Microarray Analysis}

The gene expression profile of GSE11583 was downloaded from the GEO database (http://www.ncbi. nlm.nih.gov/geo), which was based on the GPL2986 platform of the ABI Human Genome Survey Microarray Version 2. This expression profiling of array-detected differences in endothelial cell gene expression was regulated by collateral flow (normal group vs remodeling group) [17].

Data preprocessing, such as normalization and log2 transformation of the values, was performed using the limma package from Bioconductor in R. Probe-level data with a missing value or a value less than 1 were discarded. Furthermore, the probe-level data were converted to gene expression values. When several probes corresponded to one gene symbol, the maximal value of the probe-level data represented the gene expression value. Quartile data normalization was performed before discovering differentially expressed genes (DEGs). Principal component analysis (PCA) was used to determine expression profiling of the samples. A t-test analysis was used to identify DEGs between the two groups. Then, the log2 fold-change was calculated. The raw P-values were adjusted into a false discovery rate (FDR) using the Benjamin and Hochberg method [18], which avoided too many false positive results due to the multi-test problem. Then FDR $<0.05$ and $\mid \log _{2}$ Fold Change (FC) $\mid>1$ were used as the cut-off criteria to identify the ultimate DEGs. A cluster analysis was used to group the samples into clusters according to DEGs.

To analyze pathway enrichment of DEGs, Gene set enrichment analysis (GSEA) was performed on upregulated and downregulated genes using the Kyoto Encyclopedia of Genes and Genomes (KEGG) database [19]. Only gene sets with an enrichment $\mathrm{P}$ value $<0.05$ and FDR $<0.25$ were considered to be significantly enriched. To explore hub genes, protein-protein interaction (PPI) networks were constructed. Given that most of the networks were scale-free, the hub genes with high degrees were selected [20].

\section{Statistical analysis}

SPSS software version 22.0 was used for statistical analysis. Continuous variables were presented as the mean $\pm \mathrm{SD}$, and Student's t-test was used to assess the significance of differences between the two groups. A Chi-square test was performed to test for differences between categorical variables, such as the male/female ratio and stenosis site. A P $<0.05$ was considered to be statistically significant.

\section{Results}

\section{Classification by CTA}

From January 2015 to December 2016, 175 patients were enrolled in the study, including 133 males and 42 females. According to CTA criteria, those patients were divided into a mild group $(n=98)$ and a severe group $(n=77)$. Basic demographic factors and clinical characteristics are shown in Table 1. There was no significant differences in age, male/ female ratio and stenosis site between the two groups.

\section{Serum analysis}

The data are shown in Fig. 1. In the mild group, calcium was $2.21 \pm 0.08$ $\mathrm{mmol} / \mathrm{L}$ compared to $2.27 \pm 0.08 \mathrm{mmol} / \mathrm{L}$ in the severe group $(\mathrm{P}<0.01)$. Uric acid was $329.11 \pm 86.76 \mu \mathrm{mol} / \mathrm{L}$ in the mild group and $331.12 \pm 97.31 \mu \mathrm{mol} / \mathrm{L}$ in the severe group $(\mathrm{P}=0.89)$. Low density lipoprotein was $2.86 \pm 0.90 \mathrm{mmol} / \mathrm{L}$ in the mild group and $3.00 \pm 0.94 \mathrm{mmol} / \mathrm{L}$ in the severe group $(\mathrm{P}=0.32)$. Homocysteine was $15.96 \pm 15.40$ $\mu \mathrm{mol} / \mathrm{L}$ in the mild group and $13.03 \pm 6.58$ $\mu \mathrm{mol} / \mathrm{L}$ in the severe group $(\mathrm{P}=0.12)$.
Table. 1. Comparison of demographic factors and clinical characteristics between the two groups

\begin{tabular}{|c|c|c|c|}
\hline & \multicolumn{2}{|c|}{ Occlusion degree } & \multirow{2}{*}{$\mathrm{P}$} \\
\hline & Mild (\%) & Sever(\%) & \\
\hline Age & $\begin{array}{r}6 \\
3.3 \pm 8.7\end{array}$ & $\begin{array}{r}6 \\
4.1 \pm 7.8\end{array}$ & .55 \\
\hline Sex & & & .59 \\
\hline males & $6(77.6)$ & $\begin{array}{r}5 \\
7(74.0)\end{array}$ & \\
\hline females & $\begin{array}{r}2 \\
2(22.4)\end{array}$ & $0(26.0)$ & \\
\hline Occlusion site & & & .15 \\
\hline intracranial vessels & $0(71.4)^{7}$ & $7(61.0)^{4}$ & \\
\hline intracranial and extracranial vessels & $8(28.6)^{2}$ & $0(39.0)^{3}$ & \\
\hline
\end{tabular}


Microarray data processing

Since probe-level data with missing values or less than 1 were discarded and the maximal value of the multiple probelevel data representing the same gene was adopted, 6417 genes were included in analysis overall. After quartile data normalization, the medians were on a straight line, which indicated that the raw data were normalized successfully (Fig. 2A). PCA showed the expression profiling was different between the normal group and the remodeling group (Fig. 2B).

\section{Identification of DEGs and cluster analysis}

The DEGs, including the upregulated and downregulated genes, were identified from the normal group and the remodeling group with FDR $<0.05$ and $\left|\log _{2} \mathrm{FC}\right|>1$. As a result, a total of 91 DEGs were obtained after data processing. Compared to the normal group, there were 51 upregulated genes and 40 downregulated genes in the remodeling group (see Table. 2).

The clustering of DEGs showed that the signature of the normal group resembled each other rather than one of the remodeling group signatures and vice versa (Fig. 3). There were clear differences between the normal group and the remodeling group according to their gene expression profiles.

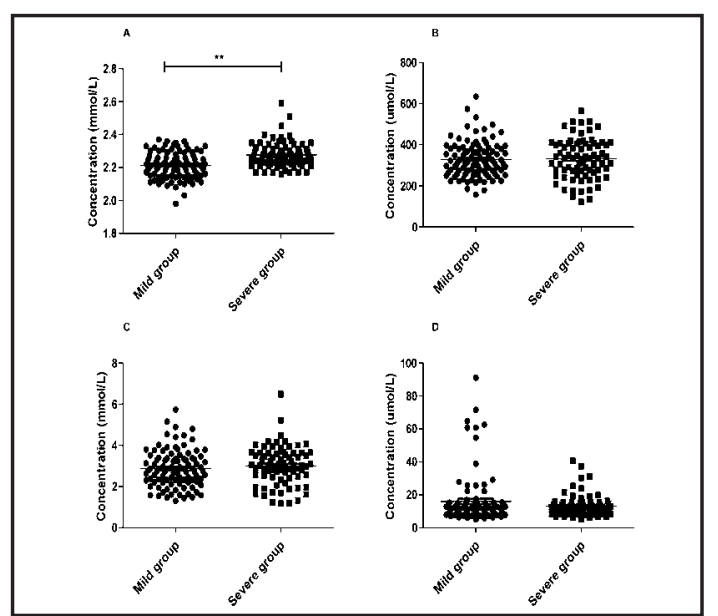

Fig. 1. Serum levels of calcium, uric acid, lowdensity lipoprotein and homocysteine between the two groups. (A) Serum calcium levels $(\mathrm{P}<0.01)$. (B) Serum uric acid levels $(\mathrm{P}=0.89)$. (C) Serum low-density lipoprotein levels $(\mathrm{P}=0.32)$. (D) Serum homocysteine levels $(\mathrm{P}=0.12)$.
Table 2. DEGs between the two groups (severe group vs mild group) FDR, false discovery rate

\begin{tabular}{|c|c|c|c|c|}
\hline & & $\log 2 \mathrm{FC}$ & P Value & FDR \\
\hline \multirow[t]{51}{*}{ Upregulated } & PLAT & 3.494 & $7.31 \mathrm{E}-07$ & 0.0028 \\
\hline & ADAMTS1 & 3.430 & $3.39 \mathrm{E}-05$ & 0.0156 \\
\hline & SLCO2A1 & 3.114 & $5.60 \mathrm{E}-05$ & 0.0180 \\
\hline & AKR1B1 & 3.043 & 7.45E-06 & 0.0060 \\
\hline & AKR1C4 & 2.785 & $1.73 \mathrm{E}-05$ & 0.0111 \\
\hline & PLPP1 & 2.670 & $6.02 \mathrm{E}-06$ & 0.0055 \\
\hline & C9orf3 & 2.579 & $2.10 \mathrm{E}-06$ & 0.0043 \\
\hline & PTHLH & 2.568 & 0.0002776 & 0.0371 \\
\hline & AKR1C1 & 2.548 & 0.0005782 & 0.0459 \\
\hline & SLCO4A1 & 2.547 & 0.0004517 & 0.0443 \\
\hline & KLF2 & 2.432 & $2.72 \mathrm{E}-05$ & 0.0144 \\
\hline & ID1 & 2.230 & $5.00 \mathrm{E}-06$ & 0.0053 \\
\hline & MRPS6 & 2.216 & $4.61 \mathrm{E}-06$ & 0.0053 \\
\hline & DUSP5 & 2.213 & 0.0003809 & 0.0407 \\
\hline & IFIT2 & 2.193 & 0.0001326 & 0.0258 \\
\hline & BFSP1 & 2.130 & $1.91 \mathrm{E}-05$ & 0.0111 \\
\hline & ADAM19 & 2.126 & $2.93 \mathrm{E}-05$ & 0.0144 \\
\hline & PMP22 & 2.096 & 0.0002033 & 0.0343 \\
\hline & NDRG1 & 2.079 & $6.46 \mathrm{E}-05$ & 0.0183 \\
\hline & FGF18 & 2.062 & 0.0003023 & 0.0376 \\
\hline & SMAGP & 2.021 & $6.19 \mathrm{E}-05$ & 0.0183 \\
\hline & TIMP3 & 1.992 & 0.0002004 & 0.0343 \\
\hline & ME1 & 1.970 & $4.11 \mathrm{E}-05$ & 0.0165 \\
\hline & THBD & 1.949 & 0.0006194 & 0.0481 \\
\hline & APOL2 & 1.949 & 0.0005038 & 0.0456 \\
\hline & ATP1B1 & 1.904 & 0.0002939 & 0.0376 \\
\hline & ABCB 6 & 1.835 & $5.29 \mathrm{E}-05$ & 0.0179 \\
\hline & CD58 & 1.816 & $5.03 \mathrm{E}-05$ & 0.0179 \\
\hline & TBC1D3C & 1.802 & $9.54 \mathrm{E}-05$ & 0.0211 \\
\hline & LMO7 & 1.749 & 0.0002738 & 0.0371 \\
\hline & METTL7A & 1.741 & 0.0005341 & 0.0456 \\
\hline & NFKBIA & 1.707 & 0.0001396 & 0.0263 \\
\hline & LDB2 & 1.673 & $6.56 \mathrm{E}-05$ & 0.0183 \\
\hline & NQO1 & 1.664 & 0.000305 & 0.0376 \\
\hline & IFIT3 & 1.611 & 0.0006744 & 0.0497 \\
\hline & EMP3 & 1.578 & 0.0006935 & 0.0497 \\
\hline & ZBTB47 & 1.462 & 0.0005718 & 0.0459 \\
\hline & РPT2 & 1.440 & 0.0003517 & 0.0394 \\
\hline & ABI3 & 1.429 & 0.0001701 & 0.0312 \\
\hline & PALM & 1.429 & 0.0005396 & 0.0456 \\
\hline & ISYNA1 & 1.364 & 0.0005393 & 0.0456 \\
\hline & MEDAG & 1.359 & 0.000495 & 0.0456 \\
\hline & CALML4 & 1.332 & 0.0002841 & 0.0372 \\
\hline & AMDHD2 & 1.326 & 0.0006855 & 0.0497 \\
\hline & JAG1 & 1.318 & 0.0005227 & 0.0456 \\
\hline & PIK3C2B & 1.313 & 0.0002575 & 0.0359 \\
\hline & MKNK2 & 1.285 & 0.0003372 & 0.0386 \\
\hline & FRY & 1.278 & 0.0007083 & 0.0499 \\
\hline & CDKN2D & 1.226 & 0.0006943 & 0.0497 \\
\hline & ADAM15 & 1.208 & 0.0005657 & 0.0459 \\
\hline & FBN1 & 1.197 & 0.0005073 & 0.0456 \\
\hline Downregulated & RBMXL1 & -1.191 & 0.0006217 & 0.0481 \\
\hline & SMS & -1.206 & 0.000557 & 0.0459 \\
\hline & TUBB & -1.216 & 0.0003918 & 0.0412 \\
\hline & PTPRD & -1.229 & 0.0006971 & 0.0497 \\
\hline & CERK & -1.258 & 0.0002435 & 0.0359 \\
\hline & GIMAP4 & -1.330 & 0.0002376 & 0.0359 \\
\hline & TMEM237 & -1.332 & 0.0004414 & 0.0443 \\
\hline & ESM1 & -1.344 & 0.0004998 & 0.0456 \\
\hline & DACH1 & -1.413 & 0.000327 & 0.0386 \\
\hline & CLEC1A & -1.450 & 0.0004623 & 0.0443 \\
\hline & LOX & -1.462 & 0.0003186 & 0.0386 \\
\hline & TNFSF4 & -1.467 & 0.0005798 & 0.0459 \\
\hline & BMP2 & -1.470 & 0.0004373 & 0.0443 \\
\hline & WFS1 & -1.489 & 0.0006612 & 0.0497 \\
\hline & CD93 & -1.536 & 0.0002243 & 0.0359 \\
\hline & CTGF & -1.537 & 0.0003372 & 0.0386 \\
\hline & BMP4 & -1.551 & 0.0002386 & 0.0359 \\
\hline & CALD1 & -1.555 & $9.42 \mathrm{E}-05$ & 0.0211 \\
\hline & MYH10 & -1.636 & 0.0001234 & 0.0253 \\
\hline & TRIP13 & -1.637 & 0.0004598 & 0.0443 \\
\hline & P4HA3 & -1.655 & 0.0002504 & 0.0359 \\
\hline & LXN & -1.659 & 0.0001881 & 0.0335 \\
\hline & DUSP6 & -1.684 & 0.0003557 & 0.0394 \\
\hline & NREP & -1.704 & 0.0004476 & 0.0443 \\
\hline & TCF4 & -1.723 & 0.0001262 & 0.0253 \\
\hline & FAM89A & -1.749 & $4.08 \mathrm{E}-05$ & 0.0165 \\
\hline & CCL14 & -1.755 & 0.0006644 & 0.0497 \\
\hline & EDN1 & -1.832 & 0.000234 & 0.0359 \\
\hline & TUBB3 & -1.835 & $7.73 \mathrm{E}-05$ & 0.0185 \\
\hline & LIMS3 & -1.957 & 7.53E-05 & 0.0185 \\
\hline & CXCL8 & -1.970 & 4.47E-05 & 0.0169 \\
\hline & THBS1 & -1.987 & $7.61 \mathrm{E}-05$ & 0.0185 \\
\hline & RGCC & -2.157 & 0.0002539 & 0.0359 \\
\hline & PBK & -2.193 & 0.0005233 & 0.0456 \\
\hline & ANLN & -2.193 & $7.80 \mathrm{E}-05$ & 0.0185 \\
\hline & MTUS1 & -2.347 & $2.68 \mathrm{E}-06$ & 0.0043 \\
\hline & CSGALNACT1 & -2.387 & 0.0001073 & 0.0230 \\
\hline & CCL2 & -2.468 & $1.06 \mathrm{E}-05$ & 0.0076 \\
\hline & FABP4 & -2.979 & 0.0003619 & 0.0394 \\
\hline & C10orf10 & -4.344 & $8.82 \mathrm{E}-07$ & 0.0028 \\
\hline
\end{tabular}


Identification of diseases related to DEGs

To confirm whether this dataset was suitable for analyzing stroke, we performed disease enrichment analysis based on DEGs using STRINGdb package in $R$. The upregulated genes were significantly related to cardiovascular system disease, artery disease and vascular disease. The downregulated genes were significantly related to vascular disease, atherosclerosis and arteriosclerotic cardiovascular disease (Table. 3).

\section{Pathway enrichment analysis}

To inspect the biological pathways associated with DEGs, we employed the GSEA method. The upregulated genes were only linked to the phosphatidylinositol signaling system (Table. 4). On the other hand, the downregulated genes were significantly associated with the cell cycle, DNA replication and cytokine-cytokine receptor interaction (Table. 4).

\section{PPI network and hub genes}

Within a PPI network, each node indicated a gene, while the edges represented for the interactions between nodes. The degree represents the number of edges linked to a given node. Thus, nodes with a high degree $(n \geq 8)$ were defined as hub genes that assumed important biological functions. A total of 3 hub genes were selected from the upregulated PPI network, which were KLF2, NFKBIA and TIMP3 with connectivity degrees of eight (Fig. 4A). Meanwhile, 9 hub genes were identified from the downregulated PPI network (Fig. 4B).

\section{Discussion}

The association between stroke and serum uric acid has been widely studied. For example, patients with uric acid concentrations in the highest quintile were associated with cardioembolic stroke [21]. A meta-analysis indicated that the serum uric acid level had a protective effect on neurological outcomes after acute ischemic stroke [22]. Further study showed elevated serum uric acid was positively associated with a better prognosis in men, but not in women [23]. In the present study, we did not find an association between the degree of artery stenosis and uric acid.

Epidemiological studies have identified a close relationship between acute ischemic

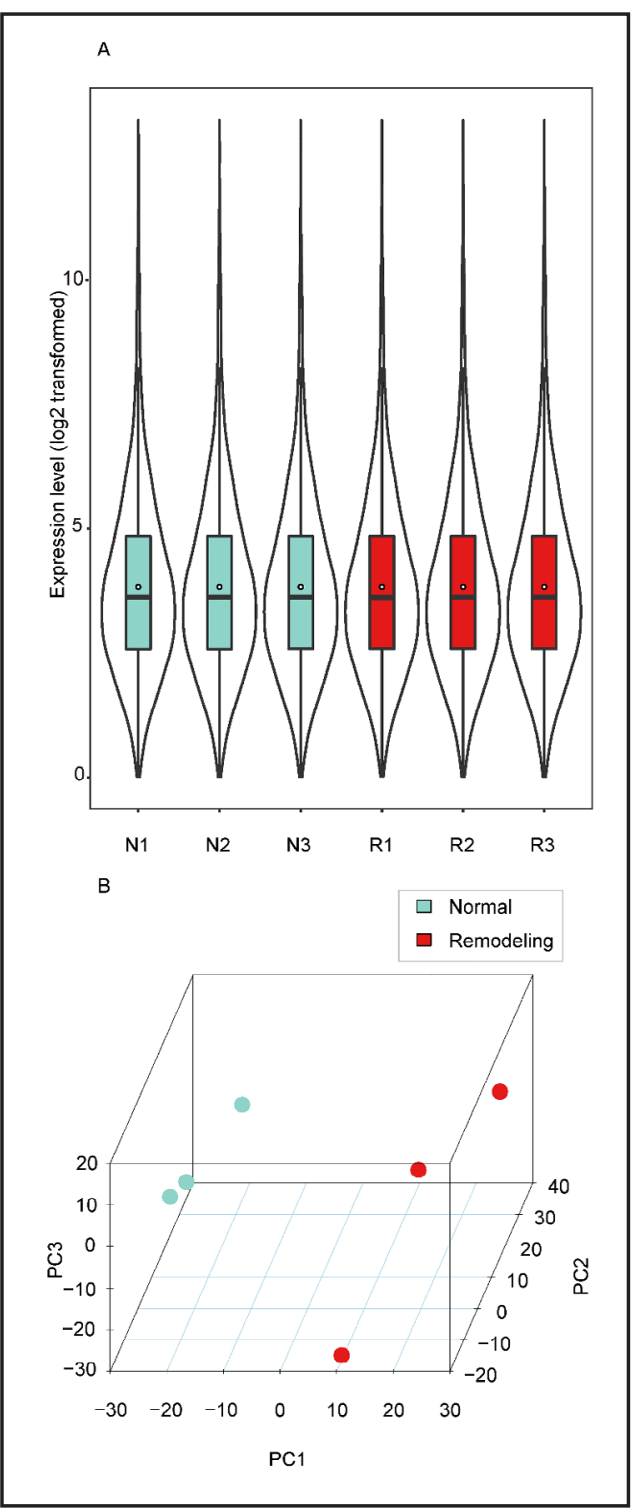

Fig. 2. Microarray data processing. (A) The expression distribution characteristics of the dataset after quartile data normalization. (B) PCA showed a normal group and remodeling group were clearly set apart from each other. N1-N3: samples from the normal group; R1-R3: samples from the remodeling group.

Table 3. Diseases that are Overrepresented in DEGs. FDR, false discovery rate

\begin{tabular}{|c|c|c|c|c|c|}
\hline & Term & Protein Numbers & Hits & P Value & FDR \\
\hline \multirow[t]{3}{*}{ Upregulated } & Cardiovascular system disease & 1360 & 19 & $\begin{array}{c}6.81 \mathrm{E} \\
-11\end{array}$ & $1.36 \mathrm{E}-07$ \\
\hline & Artery disease & 962 & 15 & $\begin{array}{c}2.78 \mathrm{E} \\
-09\end{array}$ & $1.27 \mathrm{E}-06$ \\
\hline & Vascular disease & 1146 & 16 & $\begin{array}{c}3.49 \mathrm{E} \\
-09\end{array}$ & $1.27 \mathrm{E}-06$ \\
\hline \multirow[t]{3}{*}{ Downregulated } & Vascular disease & 1146 & 20 & $\begin{array}{c}1.01 \mathrm{E} \\
-15\end{array}$ & 7.64E-13 \\
\hline & Atherosclerosis & 389 & 14 & $\begin{array}{c}4.09 \mathrm{E} \\
-15\end{array}$ & $8.46 \mathrm{E}-13$ \\
\hline & Artery disease & 962 & 18 & $\begin{array}{c}1.49 \mathrm{E} \\
-14\end{array}$ & $2.26 \mathrm{E}-12$ \\
\hline
\end{tabular}




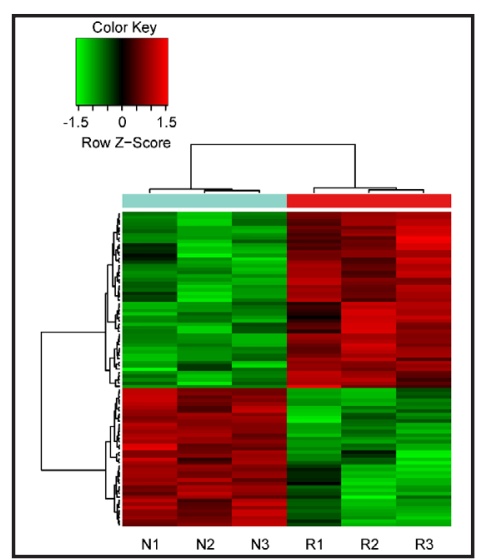

Fig. 3. Heatmap of DEGs between the normal group and the remodeling group as well as hierarchical cluster analysis. Red: upregulated DEGs; green: downregulated DEGs; N1N3: samples from the normal group; R1-R3: samples from the remodeling group.

stroke and dyslipidemia. Low density lipoprotein is one of serum lipids that can be used to predict the location of atherosclerotic lesions. Patients with extracranial lesions had a significantly lower level of low density lipoprotein compared to patients with intracranial lesions [24]. In our study, compared to the normal group, the severe group had a tendency to contain higher levels of low density lipoprotein but the differences in those levels were not significant.

An elevated serum homocysteine level is an established risk factor for acute ischemic stroke. In Chinese people, hyperhomocysteinemia is an independent risk factor for the degree of carotid artery atherosclerosis [25]. A segment-specific study confirmed a positive effect of elevated homocysteine on the intima-media thickness at the internal carotid artery rather than the common carotid artery [26]. Unfortunately, our results did not suggest there was an association between the degree of artery stenosis and homocysteine.

Numerous studies have focused on the serum levels of calcium after acute ischemic stroke. However, the pathophysiological role played by calcium is still largely unknown. Two recent studies had conflicted conclusions. Chung JW et al. reported poorer short-term outcomes and greater risks of long-term mortality with elevated serum calcium levels after acute ischemic stroke [27]. In contrast, calcium supplementation for acute ischemic stroke had potential benefits [28]. Admittedly, stroke is a complex pathophysiological process that leads to neuronal cell death or apoptosis through imbalance of ion homeostasis, acidosis, free radical-mediated lipid oxidation, and other processes. All of these changes result in fluctuation of serum calcium levels. It is difficult to confirm the major source of calcium alternation after acute ischemic stroke. In this study, we tried to solve the problem using endothelial cells under turbulent collateral blood flow.

The residual blood flow velocity was decreased near the occlusion location [29]. In addition to intrinsic basilar artery stenosis, high-grade stenosis of the internal carotid KARGER 
artery or vertebral artery can greatly contribute to induce an elevated blood flow velocity in the basilar artery [12]. The altered local hemodynamic changes produced vessel shear stress that acted on endothelial cells, which will regulate the gene expression of endothelial cells. The disease enrichment analysis based on DEGs showed these DEGs were related to vascular diseases, especially atherosclerosis. Therefore, the dataset GSE11583 provided a framework to better understand the remodeling of endothelial cells after acute ischemic stroke [17]. Pathway enrichment analysis indicated that upregulated genes were only significantly linked with the phosphatidylinositol signaling system. This signaling system functioned as a second messenger system for a variety of extracellular signals. According to the KEGG database, one of the downstream targets of the phosphatidylinositol signaling system is Protein kinase $\mathrm{C}$ (PKC) and the calcium signaling pathway. PKC could inhibit the $\mathrm{Ca}^{2+}$ influx through voltagesensitive $\mathrm{Ca}^{2+}$ channels [30]. This inhibition may be a partial reason for the phenomenon in which the serum level of calcium was higher in patients with more severe artery stenosis lesions. Indeed, the phosphatidylinositol signaling system mediated inflammatory signaling during atherogenesis [31].

Among the upregulated hub genes, endothelial KLF2, which is a member of the zinc finger family of transcription factors, is a key regulator of the blood brain barrier function and a neuroprotective factor in ischemic stroke [32]. Additionally, endothelial KLF2 has been shown to control smooth muscle migration [17]. NFKBIA inhibited NF-кB/REL complexes, which are involved in inflammatory responses. It was reported that attenuation of activation of NF- $\mathrm{KB} / \mathrm{p} 65$ prevented apoptosis caused by transient focal ischemia in neurons [33]. Very high wall shear stress on endothelial cells upregulated TIMP3 [34]. Polymorphisms in TIMP3 showed a significant trend test for linearity with increasing copy number and increased intima-media thickness of the internal carotid artery bulb [35]. In our study, these genes were upregulated in the severe group, which agreed with the results of previous studies. These upregulated genes could be the cause or the result of abnormal hemodynamic blood flow after acute ischemic stroke, which needed further research.

The main limitation of our study was that the difference in the concentration of calcium in serum between the two groups was very small, even though there was a significant difference. In addition, we did not consider the potential impact of factors other than stroke on serum calcium level in our analysis. Higher serum calcium level may be the result of confounding factors. Therefore, to better understand the pathophysiological changes in endothelial cells after acute ischemic stroke, a metabolomics study needs to be conducted in future research.

\section{Conclusion}

Our study showed that the serum level of calcium is higher in patients with a more severe artery stenosis lesion, and the phosphatidylinositol signaling system plays an important role in this process. Some hub genes identified from the perspective of endothelial cells under turbulent blood flow provide not only insights into the pathophysiological properties of acute ischemic stroke but also a clue and direction for the prevention and treatment of atherosclerosis in carotid arteries.

\section{Acknowledgements}

The authors appreciate the coordination from the stroke survivors and their caregivers The authors also thank all the diligence from therapists and evaluators involved in this study. This work is construction funds for stroke prevention and treatment center in Shanghai. 


\section{Cellular Physiology Cell Physiol Biochem 2018;46:1189-1197 \begin{tabular}{ll|l} 
and Biochemistry Published onIIne: April 19, 2018 & $\begin{array}{l}\text { C) } 2018 \text { The Author(s). Published by S. Karger AG, Basel } \\
\text { www.karger.com/cpb }\end{array}$ \\
\hline
\end{tabular} \\ Wu et al.: Serum Calcium and Artery Stenosis}

\section{Disclosure Statement}

No conflict of interests exists.

\section{References}

1 Broderick JP, Palesch YY, Demchuk AM, Yeatts SD, Khatri P, Hill MD, Jauch EC, Jovin TG, Yan B, Silver FL, von Kummer R, Molina CA, Demaerschalk BM, Budzik R, Clark WM, Zaidat 00, Malisch TW, Goyal M, Schonewille WJ, Mazighi M, Engelter ST, Anderson C, Spilker J, Carrozzella J, Ryckborst KJ, Janis LS, Martin RH, Foster LD, Tomsick TA, Interventional Management of Stroke IIII: Endovascular therapy after intravenous t-PA versus t-PA alone for stroke. N Engl J Med 2013;368:893-903.

-2 Brozici M, van der Zwan A, Hillen B: Anatomy and functionality of leptomeningeal anastomoses: a review. Stroke 2003;34:2750-2762.

3 Christoforidis GA, Mohammad Y, Kehagias D, Avutu B, Slivka AP: Angiographic assessment of pial collaterals as a prognostic indicator following intra-arterial thrombolysis for acute ischemic stroke. AJNR Am J Neuroradiol 2005;26:1789-1797.

4 Chuang YM, Chan L, Lai YJ, Kuo KH, Chiou YH, Huang LW, Kwok YT, Lai TH, Lee SP, Wu HM, Yeh YC: Configuration of the circle of Willis is associated with less symptomatic intracerebral hemorrhage in ischemic stroke patients treated with intravenous thrombolysis. J Crit Care 2013;28:166-172.

-5 Shimoyama T, Shibazaki K, Kimura K, Uemura J, Shiromoto T, Watanabe M, Inoue T, Iguchi Y, Mochio S: Admission hyperglycemia causes infarct volume expansion in patients with ICA or MCA occlusion: association of collateral grade on conventional angiography. Eur J Neurol 2013;20:109-116.

6 Rai AT, Jhadhav Y, Domico J, Hobbs GR: Procedural predictors of outcome in patients undergoing endovascular therapy for acute ischemic stroke. Cardiovasc Intervent Radiol 2012;35:1332-1339.

7 Kinoshita T, Ogawa T, Kado H, Sasaki N, Okudera T: CT angiography in the evaluation of intracranial occlusive disease with collateral circulation: comparison with MR angiography. Clin Imaging 2005;29:303306.

-8 Patrick JT, Fritz JV, Adamo JM, Dandonna P: Phase-contrast magnetic resonance angiography for the determination of cerebrovascular reserve. J Neuroimaging 1996;6:137-143.

-9 Pindzola RR, Balzer JR, Nemoto EM, Goldstein S, Yonas H: Cerebrovascular reserve in patients with carotid occlusive disease assessed by stable xenon-enhanced ct cerebral blood flow and transcranial Doppler. Stroke 2001;32:1811-1817.

10 Kim Y, Sin DS, Park HY, Park MS, Cho KH: Relationship between flow diversion on transcranial Doppler sonography and leptomeningeal collateral circulation in patients with middle cerebral artery occlusive disorder. J Neuroimaging 2009;19:23-26.

-11 Lee JH, Kim YJ, Choi JW, Roh HG, Chun YI, Cho HJ, Kim HY: Multimodal CT: favorable outcome factors in acute middle cerebral artery stroke with large artery occlusion. Eur Neurol 2013;69:366-374.

12 Zhong J, Chen XY, Leung TW, Ou A, Shi X, Cai Y, Huang Y, Wong KS: Significance of Raised Flow Velocity in Basilar Artery in Patients with Acute Ischemic Stroke: Focal Stenosis, Coexistent Stenosis, and Collateral Flow. J Neuroimaging 2015;25:922-926.

-13 Davies PF: Flow-mediated endothelial mechanotransduction. Physiol Rev 1995;75:519-560.

14 Chien S: Mechanotransduction and endothelial cell homeostasis: the wisdom of the cell. Am J Physiol Heart Circ Physiol 2007;292:H1209-1224.

15 Samuels OB, Joseph GJ, Lynn MJ, Smith HA, Chimowitz MI: A standardized method for measuring intracranial arterial stenosis. AJNR Am J Neuroradiol 2000;21:643-646.

-16 North American Symptomatic Carotid Endarterectomy Trial C: Beneficial effect of carotid endarterectomy in symptomatic patients with high-grade carotid stenosis. N Engl J Med 1991;325:445-453.

17 Mack PJ, Zhang Y, Chung S, Vickerman V, Kamm RD, Garcia-Cardena G: Biomechanical Regulation of Endothelium-dependent Events Critical for Adaptive Remodeling. J Biol Chem 2009;284:8412-8420.

18 Nakaoka H, Tajima A, Yoneyama T, Hosomichi K, Kasuya H, Mizutani T, Inoue I: Gene expression profiling reveals distinct molecular signatures associated with the rupture of intracranial aneurysm. Stroke 2014;45:2239-2245. 


\section{Cellular Physiology Cell Physiol Biochem 2018;46:1189-1197

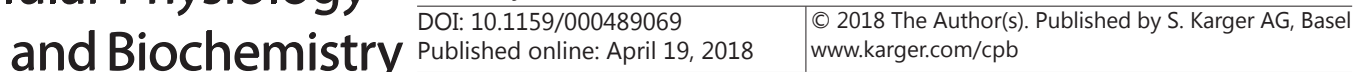

19 Tarca AL, Draghici S, Khatri P, Hassan SS, Mittal P, Kim JS, Kim CJ, Kusanovic JP, Romero R: A novel signaling pathway impact analysis. Bioinformatics 2009;25:75-82.

20 Kou Y, Zhang S, Chen X, Hu S: Gene expression profile analysis of colorectal cancer to investigate potential mechanisms using bioinformatics. Onco Targets Ther 2015;8:745-752.

-21 Yang XL, Kim Y, Kim TJ, Jung S, Kim CK, Lee SH: Association of serum uric acid and cardioembolic stroke in patients with acute ischemic stroke. J Neurol Sci 2016;370:57-62.

-22 Wang Z, Lin Y, Liu Y, Chen Y, Wang B, Li C, Yan S, Wang Y, Zhao W: Serum Uric Acid Levels and Outcomes After Acute Ischemic Stroke. Mol Neurobiol 2016;53:1753-1759.

-23 Chen LH, Zhong C, Xu T, Xu T, Peng Y, Wang A, Wang J, Peng H, Li Q Ju Z, Geng D, Zhang J, Li Y, Zhang Y, He J: Sex-specific Association Between Uric Acid and Outcomes After Acute Ischemic Stroke: A Prospective Study from CATIS Trial. Sci Rep 2016;6:38351.

24 Suwanwela NC, Chutinet A, Phanthumchinda K: Inflammatory markers and conventional atherosclerotic risk factors in acute ischemic stroke: comparative study between vascular disease subtypes. J Med Assoc Thai 2006;89:2021-2027.

25 Wang H, Fan D, Zhang H, Fu Y, Zhang J, Shen Y: Serum level of homocysteine is correlated to carotid artery atherosclerosis in Chinese with ischemic stroke. Neurol Res 2006;28:25-30.

26 Dietrich M, Jacques PF, Polak JF, Keyes MJ, Pencina MJ, Evans JC, Wolf PA, Selhub J, Vasan RS, D’Agostino RB: Segment-specific association between plasma homocysteine level and carotid artery intima-media thickness in the Framingham Offspring Study. J Stroke Cerebrovasc Dis 2011;20:155-161.

$\checkmark 27$ Chung JW, Ryu WS, Kim BJ, Yoon BW: Elevated calcium after acute ischemic stroke: association with a poor short-term outcome and long-term mortality. J Stroke 2015;17:54-59.

28 Gupta A, Prabhakar S, Modi M, Bhadada SK, Kalaivani M, Lal V, Khurana D: Effect of Vitamin D and calcium supplementation on ischaemic stroke outcome: a randomised controlled open-label trial. Int J Clin Pract 2016;70:764-770.

-29 Alexandrov AV, Burgin WS, Demchuk AM, El-Mitwalli A, Grotta JC: Speed of intracranial clot lysis with intravenous tissue plasminogen activator therapy: sonographic classification and short-term improvement. Circulation 2001;103:2897-2902.

-30 MacNicol M, Schulman H: Cross-talk between protein kinase C and multifunctional Ca2+/calmodulindependent protein kinase. J Biol Chem 1992;267:12197-12201.

-31 Chang JD, Sukhova GK, Libby P, Schvartz E, Lichtenstein AH, Field SJ, Kennedy C, Madhavarapu S, Luo J, Wu D, Cantley LC: Deletion of the phosphoinositide 3-kinase p110gamma gene attenuates murine atherosclerosis. Proc Natl Acad Sci U S A 2007;104:8077-8082.

-32 Shi H, Sheng B, Zhang F, Wu C, Zhang R, Zhu J, Xu K, Kuang Y, Jameson SC, Lin Z, Wang Y, Chen J, Jain MK, Atkins GB: Kruppel-like factor 2 protects against ischemic stroke by regulating endothelial blood brain barrier function. Am J Physiol Heart Circ Physiol 2013;304:H796-805.

-33 Liang J, Luan Y, Lu B, Zhang H, Luo YN, Ge P: Protection of ischemic postconditioning against neuronal apoptosis induced by transient focal ischemia is associated with attenuation of NF-kappaB/p65 activation. PLoS One 2014;9:e96734.

34 Dolan JM, Sim FJ, Meng H, Kolega J: Endothelial cells express a unique transcriptional profile under very high wall shear stress known to induce expansive arterial remodeling. Am J Physiol Cell Physiol 2012;302:C1109-1118.

-35 Armstrong C, Abilleira S, Sitzer M, Markus HS, Bevan S: Polymorphisms in MMP family and TIMP genes and carotid artery intima-media thickness. Stroke 2007;38:2895-2899. 